We thank all the orthopaedic surgeons at the Nottingham General Hospital for their close co-operation and for permission to study their patients and the pathologists who allowed us to perform the necropsy studies.

The study was supported by a grant for technical help and for the purchase of equipment from Boehringer Ingelheim Ltd, and we gratefully acknowledge their help.

Requests for reprints should be addressed to Dr G K Morris.

\section{References}

1 Atkins, P, and Hawkins, L A, Lancet, 1965, 2, 1217.

2 Negus, D, et al, British fournal of Surgery, 1968, 55, 835.
3 Kakkar, V V, et al, Lancet, 1970, 1, 540

${ }^{4}$ Milne, R M, et al, Lancet, 1971, 2, 445.

5 Browse, N L, et al, British Medical fournal, 1971, 4, 325.

${ }^{6}$ Myrvold, H E, et al, Acta Chirurgica Scandinavica, 1973, 139, 609.

Flanc, C, Kakkar, V V, and Clarke, M B, British fournal of Surgery, 1968, $55,742$.

${ }^{8}$ Kakkar, V V, in Thromboembolism: Diagnosis and Treatment, ed V V Kakkar and A J Jouhar, p 107. Edinburgh and London, Churchill Livingstone, 1972.

9 Barrie, W W, et al, British Medical fournal, 1974, 4, 130.

${ }^{10}$ Louden, J R, British Medical fournal, 1976, 2, 793.

${ }_{11}$ Morris, G K, and Mitchell, J R A, Lancet, 1976, 2, 869.

12 Browse, N L, Clemenson, G, and Croft, D N, British Medical fournal, 1974, 1, 603.

(Accepted 23 November 1976)

\title{
Fibreoptic endoscopic palliative intubation of inoperable oesophagogastric neoplasms
}

\author{
MICHAEL ATKINSON, ROGER FERGUSON
}

British Medical fournal, 1977, 1, 266-267

\begin{abstract}
Summary
Palliative intubation for inoperable malignant strictures at the cardia was done on 16 occasions in 13 patients using fibreoptic endoscopy. Preliminary dilatation was performed, and the Celestin tube was mounted on an introducer and passed over a guide wire inserted with a fibreoptic endoscope. Only one death resulted from the procedure and all the 12 patients who left hospital were swallowing satisfactorily on discharge. The method provided a simple and relatively safe means of relieving dysphagia and improving nutrition.
\end{abstract}

\section{Introduction}

Neoplasms arising at or near the cardia carry a poor prognosis. Brookes et $a l^{1}$ found patients with adenocarcinoma to have a worse outlook when this was at the cardia than when elsewhere in the stomach, and radical resection was possible in only $38.2 \%$ of their patients. The outlook for those with squamous carcinoma affecting the cardia is marginally better, ${ }^{2}$ but even so palliative treatment alone is possible in only half the patients. Rapidly progressive dysphagia is a distressing symptom demanding urgent relief if the patient is to be maintained in comfort and nutritional balance. Intubation with a funnel-ended tube pulled through the cardia at laparotomy is usually effective, ${ }^{3}{ }^{4}$ but the procedure carries a hospital mortality of about $25 \%$. This led us to explore the possibility of endoscopic intubation, so avoiding laparotomy. We describe here 16 intubations in 13 patients with neoplasms at the cardia.

\section{Patients and methods}

The 13 patients all had neoplasms occluding the cardia but in some the growth extended well up the oesophagus. The residual lumen was

General Hospital, Nottingham

MICHAEL ATKINSON, MD, FRCP, consultant physician ROGER FERGUSON, MB, MRCP, senior medical registrar usually less than $5 \mathrm{~mm}$ in diameter. Adenocarcinoma was present in 10 patients and squamous carcinoma in three. All were judged inoperable because of distant metastases or gross debility, and in one patient the growth had recurred after resection three years previously.

The diagnosis was confirmed histologically at preliminary endoscopy. General anaesthesia was used for all intubations. Under direct vision using the Olympus GIFK endoscope a guidewire was inserted through the malignant stricture into the stomach, and the lumen was dilated by passing Eder-Puestow olive dilators along the wire. The scope was passed through the stricture to assess its extent and relation to the diaphragm. In the light of this information a large-diameter Celestin tube was cut to an appropriate length and mounted on an Eder-Puestow dilator carrying a bougie just small enough to be withdrawn through the tube (see figure). A rammer, consisting of heavy duty polyvinylchloride tubing of $16 \mathrm{~mm}$ external diameter and $10 \mathrm{~mm}$ bore with a metal cone at its leading end to fit into the funnel of the Celestin tube, was mounted on the Eder-Puestow introducer and held in position by a screw clamp at its proximal end. After smearing with lubricating jelly the whole assembly was passed along the guidewire under radiological control, until its position was judged satisfactory. The screw clamp was released and the dilator with the guidewire was drawn back through the tube, which was held in place by the rammer. The rammer was finally withdrawn, leaving the Celestin tube in position.

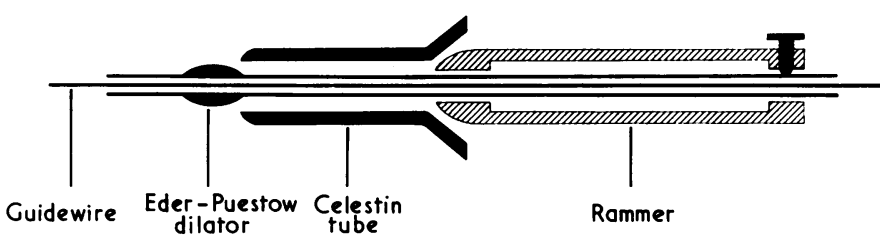

Celestin tube mounted on introducer.

The next morning a lateral chest radiograph was taken to check that the tube was in the correct position, and the patient was then allowed a soft diet washed down by effervescent drinks. On the following day a barium swallow examination was done to check that the tube was functioning normally. The patient was then allowed a more normal diet, depending on his masticatory capacity. Discharge from hospital was often possible within three days.

The degree of dysphagia was assessed before intubation, at the time of discharge from hospital, and at monthly intervals thereafter. Dysphagia was graded according to the diet the patient could take: $0=$ taking a normal diet; $1=$ unable to swallow certain solid foods 
$2=$ limited to a semisolid diet ; $3=$ limited to a liquid diet ; $4=$ unable to swallow even liquids in adequate amounts.

\section{Results}

\section{COMPLICATIONS OF ENDOSCOPIC INTUBATION}

In general the procedure was well tolerated. Mediastinitis developed in only one patient, in whom chest pain and pyrexia appeared on the day after intubation. This complication responded to conservative management and she subsequently swallowed satisfactorily up to her death six months later. The growth perforated in only one other patient, who, after leaving hospital apparently well on the third day after intubation, was readmitted three weeks later with acute peritonitis. At necropsy the growth was found to have perforated, forming an abscess cavity behind the stomach. Perforation might have resulted from a small hole caused by the guidewire, and this was the only death that may have been attributable to the procedure. One patient died of haemorrhage into a cerebral metastasis seven days after a successful intubation and the other 12 patients in the series all left hospital after the procedure.

\section{RELIEF OF DYSPHAGIA}

Before intubation three patients had grade 4 dysphagia and 10 had grade 3. In all patients there was an improvement in swallowing, which generally lasted until death. The degree of improvement varied but averaged two grades and all patients could take a semisolid diet at the time of discharge from hospital. The resulting nutritional improvement was often reflected in an increase in weight and a sense of wellbeing.

\section{TUBE FUNCTION}

Proximal tube displacement occurred in three patients. In one patient this happened within 24 hours of insertion and again within 24 hours of reinsertion of the tube. A tube with a distal shoulder was constructed and this has since remained in a satisfactory position. In the other two patients displacement occurred three and four months after insertion and in each case resulted in recurrence of severe dysphagia. $\mathrm{Re}-$ positioning of the tube restored adequate swallowing in one, but in the other the tube had to be removed and replaced by one with a distal shoulder. Further displacement has not occurred in either. In no patient did the tube pass through the stricture into the stomach.

Blockage of the tube was encountered in two patients, three weeks and two months after intubation, and in each faulty mastication appeared to be the cause. The tube was cleared at a further endoscopy in one patient, but in the other attempts to clear it were unsuccessful and it was removed and replaced at a subsequent endoscopic examination. Satisfactory swallowing was re-established in both patients and has continued for over two months.

\section{LONG-TERM OUTLOOK AFTER ENDOSCOPIC INTUBATION}

The long-term outlook after endoscopic intubation seemed to be comparable with that after intubation using laparotomy. Eight of the 13 patients died within three months of intubation, but four have survived for six months or more.

\section{Discussion}

Palliative intubation for inoperable neoplasms of the oesophagus or cardia is conventionally carried out using laparotomy, gastrotomy, and pull-through of the tube. Because patients are usually elderly and debilitated the mortality of the procedure is considerable. Ammann and Collis ${ }^{5}$ reported a hospital mortality of $31 \%$ in 29 patients undergoing Mousseau-Barbin intubation for oesophageal carcinoma. In a review of published reports Johnson et $a l^{6}$ found an overall operative mortality of $23 \%$ in 189 patients undergoing this procedure. The avoidance of operation and the preliminary dilatation of the neoplastic stricture probably accounted for the low incidence of perforation and mediastinitis and the low mortality $(7.7 \%)$ in our series.
As there was no painful upper abdominal wound we were able to mobilise and discharge the patients soon after the procedure, which substantially diminished respiratory complications.

Blind peroral intubation of a malignant stricture was first done by Symonds in 1885. T The introduction of a Souttar tube ${ }^{8}$ through the rigid oesophagoscope was a major advance in the palliation of dysphagia in patients with oesophageal carcinoma, but it proved less useful with growths at the cardia. Various flexible funnel-ended tubes have been inserted through malignant strictures by sliding them over filiform bougies ${ }^{910}$ dilators, ${ }^{11}$ lumen finders, ${ }^{12}$ or introducers ${ }^{13}$ passed under direct vision through a rigid oesophagoscope that is then removed before intubation.

Although fibreoptic endoscopy has been little used for palliative intubation, it has clear advantages in that the scope can be passed through the neoplastic stricture into the stomach and so the extent of the growth can be completely assessed before intubation. Furthermore, the method can be used in patients with gross deformity or metastases in the thoracic and cervical spine, which might preclude the use of the rigid oesophagoscope. In our view fibreoptic endoscopic placement is the method of choice for palliative intubation of inoperable oesophagogastric neoplasms.

Since the tube cannot be sutured in position with endoscopic insertion, displacement might be expected more often than with intubation at operation. Even with operative intubation, however, some surgeons find it unnecessary to suture the tube in place. ${ }^{14} \mathrm{O}^{\prime}$ Connor et al $^{10}$ found dislodgement of the tube in only nine of their 378 patients after endoscopic intubation. Tube displacement occurred in only three of our patients, which represented an incidence of one displacement per patient-year of intubation. This seems an acceptable risk since the average survival time after intubation is less than three months. ${ }^{13}$ The construction of a tube with a distal shoulder in two patients succeeded in preventing further tube displacement. Blockage of the tube may lead to vomiting and tube displacement and careful mastication is essential if this is to be prevented.

Although reflux of gastric juice through the tube was considered the most serious disadvantage of palliative intubation by Davidenko et al, ${ }^{16}$ who constructed a tube with a flutter valve at its lower end, symptoms were mild in our series and neither bleeding nor perforation from trauma to the gastric wall by the lower end of the tube occurred.

Palliative intubation under fibreoptic control provides a simple and relatively safe means of relieving disabling dysphagia and improving nutrition. It does not preclude other means of treatment such as radiotherapy or even curative resection after the patient's general health has improved through correction of the nutritional deficit.

\section{References}

${ }^{1}$ Brookes, V S, Waterhouse, J A, and Powell, D J, British Medical fournal, $1965,1,1577$.

2 Collis, J L, British Fournal of Surgery, 1971, 58, 801.

3 Mousseau, M, et al, Archives des Maladies de l'Appareil Digestif, 1956, 45, 208.

${ }^{4}$ Celestin, L R, Annals of the Royal College of Surgeons of England, 1959, $25,165$.

5 Ammann, J F, and Collis, J L, fournal of Thoracic and Cardiovascular Surgery, 1971, 61, 863.

${ }^{6}$ Johnson, I R, Balfour, T W, and Bourke, J B, Fournal of the Royal College of Surgeons of Edinburgh, 1976, 21, 225.

7 Symonds, C J, Transactions of the Clinical Society of London, 1885, 28, 155.

${ }^{8}$ Souttar, H S, British Medical fournal, 1924, 1, 782.

${ }^{9}$ Carter, M G, Fournal of Thoracic Surgery, 1954, 28, 443.

${ }^{10}$ O'Connor, T, et al, Archives of Surgery, 1963, 87, 275.

11 Boyce, H W, Geriatrics, 1973, 28, 97.

12 Lewis, R T, et al, Annals of Thoracic Surgery, 1973, 16, 148.

13 Schetrumpf, J R, Thorax, 1973, 28, 533.

14 Holden, M P, Wooler, G H, and Ionescu, M I, British fournal of Surgery, $1973,60,401$.

15 Leverment, J N, and Milne, D M, Thorax, 1974, 29, 228.

${ }_{16}$ Davidenko, N, et al, Presse Médicale, 1975, 4, 2396.

(Accepted 8 December 1976) 